\title{
Contributions
}

Jiancai Pi and Yu Zhou*

\section{International Factor Mobility, Production Cost Components, and Wage Inequality}

\begin{abstract}
The present paper establishes a two-sector monopolistic competition model to investigate how international factor mobility influences the skilledunskilled wage inequality when the monopolistically competitive sector producing final goods is characterized by various types of production cost functions. We discuss three types of production cost functions of the monopolistically competitive sector. Different types of production cost functions have different production factor components of variable and fixed costs. We find that differences in production cost components of the monopolistically competitive sector matter for the impacts of international factor mobility on the skilled-unskilled wage inequality.
\end{abstract}

Keywords: international factor mobility, production cost components, skilledunskilled wage inequality, monopolistic competition

JEL Classification: J31, L13, R34

\section{Introduction}

In today's world, the pace of economic globalization has intensified at a rapid rate. Globalization brings about new development opportunities for developing countries (see Arora and Gambardella 2004). Meanwhile, developed countries also benefit from the regional economic integration (see Arora and Gambardella 2004; Baldwin 2008; Chen 2009). However, globalization is a double-edged sword. Both developed and developing countries have experienced the growing

*Corresponding author: Yu Zhou, Department of Economics, Nanjing University, 22 Hankou Road, Nanjing 210093, P. R. China, E-mail: zhouyu_0105@hotmail.com Jiancai Pi, Department of Economics, Nanjing University, 22 Hankou Road, Nanjing 210093, P. R. China, E-mail: pi2008@nju.edu.cn 
skilled-unskilled wage inequality. For example, just as estimated by Berman, Bound, and Machin (1998) and Berman and Machin (2000), the skilledunskilled wage inequality (also called the skill premium) has gone up by $8 \%$ in a sample of 35 developed and developing economies. Other representative empirical studies on the growing wage inequality (e.g. Feenstra and Hanson 1996; Wood 1997; Feenstra and Hanson 2003; Epifani and Gancia 2008; Anwar and Sun 2012; Mehta and Hasan 2012; Eriksson, Pytliková, and Warzynski 2013; McNabb and Said 2013) also strongly support that the increased skilledunskilled wage gap prevails in the United States, European countries, Asian countries, and Latin American countries.

On the other hand, along with the process of globalization, it is common to see that skilled and unskilled immigrants, as well as foreign capital inflow and outflow, have increased worldwide. Empirical studies, typically represented by Friedberg and Hunt (1995), Mishra (2007), and Figini (2011), support the close relation between international factor mobility and the widened wage inequality. Moreover, economists also make efforts to build theoretical models to analyze such a relation. The exemplified theoretical works can be referred to $\mathrm{Wu}$ (2001), Das (2002, 2005), Marjit and Kar (2005), Anwar (2006, 2008), Oladi and Beladi (2007), Chaudhuri and Yabuuchi (2007), Yabuuchi and Chaudhuri (2007), Beladi, Chaudhuri, and Yabuuchi (2008); Beladi, Kar, and Marjit 2013), Chaudhuri (2008), Chaudhuri and Banerjee (2010), Beladi, Marjit, and Broll (2011), Marjit and Kar (2011), Oladi, Gilbert, and Beladi (2011), Zhang (2012, 2013), Pan and Zhou (2013), Pi, Zhou, and Yin (2013), and Pi and Zhou (2014). Their findings show that skilled and unskilled immigrants and inflow (or outflow) of foreign capital can unconditionally or conditionally raise the skilledunskilled wage inequality at a global level.

However, there are two aspects that are largely ignored by the abovementioned theoretical literature. The first aspect is that most of the aforementioned studies conduct their analysis on the basis of the perfect competitive production sectors, especially for the final-good production sectors. ${ }^{1}$ But the final-good production sectors (e.g. manufacturing industries, electronic industries, and services industries) often share the monopolistically competitive properties, which prevail in both developing and developed countries (see Oladi and Gilbert 2011). Such production sectors, featuring with the firm's internal increasing return to scale, play an important role in economic development. The study of monopolistic competition is of great significance both theoretically and

1 It is worth noting that Anwar $(2006,2008)$ and Zhang (2012, 2013) introduce the monopolistically competitive intermediate sectors to their theoretical models and discuss the issues related to the widening wage inequality. 
empirically, and the mainstream studies are usually based on the Dixit-Stiglitz type monopolistic competition model (see Dixit and Stiglitz 1977; Helpman and Krugman 1985; Fujita, Krugman, and Venables 1999; Combes, Mayer, and Thisse 2008). However, tiny studies pay attention to the relation between international factor mobility and the growing wage inequality, particularly with an eye to the monopolistically competitive final-good production sector.

The second aspect is that the current studies ignore the impact of international factor mobility on the skilled-unskilled wage inequality when the production sectors (particularly the monopolistically competitive production sectors) possess different types of production cost functions. As is well known, cost items in the cost function include both variable and fixed ones. Different types of production cost functions have different production factor components of variable and fixed costs (see Combes, Mayer, and Thisse 2008, Chapter 3), which is called different production cost components by the present paper. ${ }^{2}$ The existing literature on the skilled-unskilled wage inequality neglects to take different cost components of the monopolistically competitive final-good production sector into account. Intuitively, international factor mobility will attribute to the reallocation of economic resources among production sectors, hence leading to the change of the skilled-unskilled wage gap. Meanwhile, international factor mobility will also generate different impacts on the skilled-unskilled wage inequality if production sectors possess various cost components. Besides, the real life cases also motivate us to consider different cost components of the monopolistically competitive final-good production sector. According to Lin (2011, 201), "Economic development requires continuous introduction of new and better technology to an existing industry.... However, economic development also requires continuous diversifying and upgrading from existing industries to new, more capital-intensive ones." That is to say, with the development of economy, the technology-induced changes in production cost functions will continuously arise. In the real world, such changes in production cost functions can be artificially made by the government-oriented industrial upgrading process, typically like the East Asian economies. For example, in China, office and telecom equipment industry, machinery and transport equipment industry, and

2 In fact, the idea behind this paper comes from Combes, Mayer, and Thisse (2008, Chapter 3) to some extent, but we independently explore a research topic that is quite different from theirs. Combes, Mayer, and Thisse (2008, Chapter 3) argue that different production technologies of the monopolistically competitive sector can be shown by different production cost functions, but they seem to neglect to discuss whether different production cost functions matter for the policy impacts on the established models. In this paper, we further study the relation between wage inequality and international factor mobility under different production cost functions of the monopolistically competitive sector. 
others are generally featured with monopolistic competition and at the same time are experiencing the industry upgrading process. Such a process indicates that the cost structures of targeted industries will be changed (Lin 2011), which theoretically implies that both fixed and variable cost components of targeted industries will be changed. ${ }^{3}$

In order to fill the current research gap, we establish a two-sector monopolistic competition model to discuss how international factor mobility influences the skilled-unskilled wage inequality when a monopolistically competitive sector producing final goods is characterized by various types of production cost functions. In line with the setting of the production cost functions of the monopolistically competitive sectors in the existing literature (e.g. Sen, Ghosh, and Barman 1997; Chao, Hazari, and Yu 2006; Anwar 2009, 2010), we consider three possible production cost components of the monopolistically competitive sector. Our findings confirm that different production cost components of the monopolistically competitive sector matter for the impacts of international factor mobility on the skilled-unskilled wage inequality. Under some types of production cost functions, international factor mobility can reduce the wage inequality; however, under other types of production cost functions, international factor mobility will widen the wage gap.

The present paper makes a contribution to the current literature in the following aspects. Firstly, we explore how international factor mobility influences the skilled-unskilled wage inequality when the monopolistically competitive final-good sector is featured with different cost components. Our research angle is largely neglected by the existing studies in this field, but our conclusions show that different cost structures actually matter for the impacts of international factor mobility on the wage gap. Secondly, in the existing literature on the skilled-unskilled wage inequality, monopolistic competition usually prevails in the intermediate good sector, other than the final-good sector. Only tiny studies consider the case where final-good sectors share the feature of monopolistic competition (e.g. Das 2002, 2005; Pi, Zhou, and Yin 2013), and our paper can be treated as a supplementary to these studies.

Here we should point out that our conclusions are also of practical value (esp. for developing countries). Our conclusions tell us that under what conditions (i.e. in what types of production cost functions of the monopolistically competitive sector) international factor mobility will decrease (or increase) the

3 For example, before upgrading, some equipment industry relies highly on the assembly machineries, and thus its fixed cost mainly contains capital input. However, after upgrading, such equipment industry depends greatly on R\&D process, and thus both capital and skilled labor inputs take a large share of its fixed cost. 
skilled-unskilled wage inequality. For developing countries, the industrial upgrading policy is usually an important development policy, which is accompanied by the changes of certain industries' production cost components. Thus, when governments in developing countries help to conduct the industrial upgrading process, they should pay more attention to the production cost components that targeted industries will possess after industrial upgrading. In doing so, governments can make some pertinent policies to weaken the negative impacts (e.g. the growing skilled-unskilled wage inequality) due to international factor mobility.

The remaining parts are organized as follows. The basic theoretical model and its relevant analysis are given in Section 2. In Section 3, we consider another two possible production cost functions of the monopolistically competitive sector and comparatively reexamine the impacts generated by international factor mobility on the wage gap. Concluding remarks are provided in Section 4.

\section{The basic model}

Let us consider a small open economy which is composed of two production sectors, sector 1 and sector 2. Sector 1 is skilled-labor-intensive, employing skilled labor and capital as factors of production. Sector 2 is unskilled-laborintensive, whose production inputs include unskilled labor and capital. Capital can freely move between sector 1 and sector 2 . The products of both sectors 1 and 2 are tradable, and their prices are fixed at international levels.

In our assumed economy, sector 1 is a monopolistically competitive sector, consisting of a finite number of firms. Each firm in that sector produces only one variety of the horizontal differentiated product with the same production cost components. It is not hard to verify that the number of firms in sector 1 is equal to the number of product varieties, and the symmetric assumption is applicable to the firms in sector 1 (see Fujita, Krugman, and Venables 1999). Sector 2 is perfectly competitive, producing the homogenous product. Here the price of sector 2's product is normalized to unity.

For a representative firm in sector 1 , its total cost function can be stated as:

$$
C=f r+u x w_{S}
$$

where $C$ is the total production cost, $w_{S}$ is the wage rate of skilled labor, $r$ is the unit return of capital, $x$ is the output of the typical firm, $f r$ is the fixed cost, and $u w_{S}$ is the marginal cost. Equation (1) shows that the fixed cost is composed of only capital and the marginal cost is composed of only skilled labor. The above total cost production is also used by Anwar (2009) and Anwar (2010). 
Sector 1's profit maximization yields

$$
p\left(1-\frac{1}{\sigma}\right)=u w_{S},
$$

where $p$ is the price of sector 1's product, and $\sigma$ is the price elasticity of demand and can be set as a constant. If the consumer's preference in our assumed economy is the Dixit-Stiglitz type, the substitution elasticity among different varieties of products determines the price elasticity of demand, which can be reasonably treated as a parameter (see Helpman and Krugman 1985; Fujita, Krugman, and Venables 1999).

In the long run, the free entry condition of the monopolistically competitive market yields

$$
p x=f r+u x w_{S} .
$$

The cost minimization condition of sector 2 can be described by:

$$
1=a_{L A} w_{U}+a_{K A} r,
$$

where $w_{U}$ is the wage rate of unskilled labor, $a_{L A}$ and $a_{K A}$ are the unskilled labor and capital used to produce one unit of sector 2's product, respectively.

The full employment conditions of the factor markets are stated as:

$$
\begin{gathered}
u x n=\bar{L}_{S}, \\
f n+a_{K A} A=\bar{K}, \\
a_{L A} A=\bar{L}_{U},
\end{gathered}
$$

where $A$ is sector 2's output level, $n$ is the number of firms in sector 1, and $\bar{L}_{S}, \bar{K}$, and $\bar{L}_{U}$ are the economic endowments of skilled labor, unskilled labor, and capital, respectively. It is easy to verify that eqs (5)-(7) describe the market clearing conditions of the skilled labor market, capital market, and unskilled labor market.

In this paper, we use the ratio of the wage rate of skilled labor to that of unskilled labor (i.e. $\frac{w_{S}}{w_{U}}$ ) to describe the skilled-unskilled wage inequality. That is to say, the change of skilled-unskilled wage inequality is simply depicted by the relative change between the change rate of $w_{S}$ and that of $w_{U}$. Our notation of the skilled-unskilled wage inequality is in accord with the existing literature (e.g. Marjit, Beladi, and Chakrabarti 2004; Marjit and Kar 2005; Anwar 2006; Chao, Hazari, and Yu 2006; Chao, Laffargu, and Sgro 2012; Beladi, Chaudhuri, and Yabuuchi 2008; Pi and Zhou 2012, 2013; Pi, Zhou, and Yin 2013). 
In order to consistently compare the impacts of international factor mobility on the wage inequality under different production cost components, we would like to define the factor intensity of each sector as follows. ${ }^{4}$ Denote $k_{S}=\frac{a_{K M}}{a_{S M}}$ as the factor intensity of sector 1 and $k_{U}=\frac{a_{K A}}{a_{L A}}$ as the factor intensity of sector 2 . We define the ratio of $k_{S} / k_{U}$ as the relative factor intensity between sectors.

Now we start our following analysis. The basic theoretical model is composed of six equations, from eq. (2) to eq. (7), which determine six endogenous variables, $w_{S}, r, w_{U}, x, n$, and $A$. The exogenous variables are $\bar{L}_{S}, \bar{K}$, and $\bar{L}_{U}$. All other variables are parameters.

The impacts of international factor mobility on the skilled-unskilled wage inequality are given by Proposition 1.

Proposition 1: (i) An increase in skilled immigrants will generate no impact on the wage rate of skilled labor, but decrease the wage rate of unskilled labor. Therefore, the skilled-unskilled wage inequality will be widened. (ii) An inflow of foreign capital will not influence the wage rate of skilled labor and only raise the wage rate of unskilled labor. Thus, the skilled-unskilled wage inequality will be narrowed down. (iii) An increase in unskilled immigrants will exert no impact on the wage rate of skilled labor, but decrease the wage rate of unskilled labor, which leads to a growing skilled-unskilled wage inequality.

\section{Proof: See Appendix A.}

The economic analysis of Proposition 1 is stated as follows. When skilled labor is only embodied in the marginal cost of sector 1 , from eq. (2) we know that the price of sector 1's product will directly determine the wage rate of skilled labor. Hence, international factor mobility will generate no impact on the wage rate of skilled labor. Given the product price in sector 2, from eq. (4), we know that the change of the wage rate of unskilled labor will move in the opposite direction to that of unit capital return. Although an increase in skilled immigrants does not influence the wage rate of skilled labor, it will raise the marginal productivity of capital and thus increase the unit return of capital. This will reduce the wage rate of unskilled labor and, consequently, widen the skilled-unskilled wage inequality. This explains the first part of Proposition 1. For the second part, an inflow of foreign capital will increase the amount of capital available for the production of two sectors and, eventually, reduce the unit capital return.

4 We thank two anonymous reviewers for encouraging us to consider the role of the factor intensity. They constructively point out that we need to make a consistent assumption regarding relative factor intensity ranking between sectors. 
Therefore, the wage rate of unskilled labor will increase, and the skilledunskilled wage gap will be narrowed down. For the third part, an increase in unskilled immigrants will raise the supply of unskilled labor and lead to a reduction of the unskilled wage rate, which will attribute to a growing skilledunskilled wage inequality.

Remark 1: Proposition 1 indicates that international factor mobility exerts unambiguous impacts on the wage inequality. The reason behind this is as follows: in the presence of the cost components given by eq. (1), eq. (2) directly determines the value of $w_{S}$. International factor mobility affects the wage inequality by the way of affecting the marginal productivity of capital and hence the wage rate of unskilled labor. Therefore, the comparisons of $k_{S}$ and $k_{U}$ make no sense for the final results.

\section{Extensions and comparison}

In this section, we extend the basic theoretical model by considering the following two different production cost components of sector 1 (i.e. the monopolistically competitive industry).

\subsection{Fixed cost only uses capital and marginal cost uses both capital and skilled labor}

Then, we will discuss another possible type of the production cost function that the fixed cost only uses capital (i.e. fr) and the marginal cost uses both capital and skilled labor (i.e. $u w_{S}^{\theta} r^{1-\theta}$ ). In this situation, eq. (1) will be changed to:

$$
C=f r+u x w_{S}^{\theta} r^{1-\theta} .
$$

Such kind of production cost is also employed by Sen, Ghosh, and Barman (1997). Without loss of generality, eq. (8) can be treated as a specific example of Sen, Ghosh, and Barman (1997).

Equations (3), (5), and (6) will be changed to:

$$
\begin{gathered}
p x=f r+u x w_{S}^{\theta} r^{1-\theta}, \\
\theta u x w_{S}^{\theta-1} r^{1-\theta} n=\bar{L}_{S}, \\
{\left[f+(1-\theta) u x w_{S}^{\theta} r^{-\theta}\right] n+a_{K A} A=\bar{K} .}
\end{gathered}
$$


So far, the new model has been built, which consists of eqs (2), (4), (7), and (9)-(11). Six endogenous variables, $w_{S}, r, w_{U}, x, n$, and $A$, are determined. The exogenous variables are $\bar{L}_{S}, \bar{K}$, and $\bar{L}_{U}$. All other variables are parameters.

We establish Proposition 2 to summarize how international factor mobility influences the skilled-unskilled wage inequality.

Proposition 2: (i) An increase in skilled immigrants will decrease the wage rates of both skilled and unskilled labor. If the relative capital-labor distributive share of the variable cost in sector 1 is larger than (resp. smaller than) that in sector 2 , the skilled-unskilled wage inequality will be reduced (resp. widened). (ii) An inflow of foreign capital will raise the wage rates of both skilled and unskilled labor. If the relative capital-labor distributive share of the variable cost in sector 1 is larger than (resp. smaller than) that in sector 2, the skilled-unskilled wage inequality will be widened. (iii) An increase in the unskilled immigration will reduce the wage rates of both skilled and unskilled labor. If the relative capitallabor distributive share of the variable cost in sector 1 is larger than (resp. smaller than) the relative capital-labor distributive share in sector 2 , the skilled-unskilled wage inequality will be reduced (resp. enlarged).

\section{Proof: See Appendix B.}

It is easy to verify that international factor mobility generates the same impacts on the absolute changes of skilled and unskilled wage rates and the wage gap as those stated in Proposition 1. The economic intuitions behind Proposition 2 can be stated as follows. For the first part, an increase in skilled immigrants will raise the marginal productivity of capital as well as the unit return to capital. Given the product prices of sectors 1 and 2, a rise in the unit return to capital will decrease the wage rates of both skilled and unskilled labor. If the relative capital-labor distributive share of the variable cost in sector 1 is larger than that in sector 2, an increase in the unit return to capital will exert a larger impact on the wage rate of skilled labor, and thus the wage inequality will be reduced. On the contrary, if the relative capital-labor distributive share of the variable cost in sector 1 is smaller than that in sector 2, an increase in the unit return to capital will produce a larger impact on the wage rate of unskilled labor, and thus the wage inequality will be widened. Similarly, we can conduct the economic analyses for the second and third parts of Proposition 2.

Remark 2: From Appendix B, we can see that the relative capital-labor distributive share of the variable cost in sector 1 is $\frac{1-\theta}{\theta}$ and that in sector 2 is $\frac{\theta_{K A}}{\theta_{L A}}$. For the sake of comparison in terms of the factor intensity, we would like to use $k_{S}$ 
and $k_{U}$ to equivalently show the conditions depicted by $\frac{1-\theta}{\theta}$ and $\frac{\theta_{K A}}{\theta_{L A}}$. It is not hard to see that $\frac{1-\theta}{\theta}=k_{S} \frac{r}{w_{S}}-\frac{f}{\theta u x w_{S}^{\theta} r^{-\theta}}$ and $\frac{\theta_{K A}}{\theta_{L A}}=k_{U} \frac{r}{w_{U}}$. Hence, $\frac{1-\theta}{\theta}>(<) \frac{\theta_{K A}}{\theta_{L A}}$ is equivalent to $k_{S}-\omega k_{U}>(<) \frac{f}{\theta u x w_{S}^{\theta-1} r^{1-\theta}}$, where $\omega=\frac{w_{S}}{w_{U}}$ and is reasonably assumed to be larger than 1. The difference between Propositions 1 and 2 is that one of the wage rates cannot be independently determined by some parameter (i.e. the output price).

\subsection{Fixed cost uses capital and skilled labor and marginal cost uses capital and unskilled labor}

Finally, we will explore the case that the fixed cost is composed of skilled labor and capital (i.e. $f w_{S}^{\alpha} r^{1-\alpha}$ ) and the marginal cost is composed of unskilled labor and capital (i.e. $u w_{U}^{\theta} r^{1-\theta}$ ). In this case, production cost components of the skillintensive sector can be described by the following equation:

$$
C=f w_{S}^{\alpha} r^{1-\alpha}+u w_{U}^{\theta} r^{1-\theta} x,
$$

where $\alpha$ is a parameter and belongs to $(0,1)$.

The production cost components of eq. (12) are the same as those in Chao, Hazari, and Yu (2006). Combining eq. (12) with eq. (4), we know that in this case skilled labor is specific to the fixed cost and crucial to the external increasing return to the scale of the monopolistically competitive sector. Specifically, eq. (12) is a special case of the production cost function employed by Chao, Hazari, and $\mathrm{Yu}$ (2006).

Equations (2), (3), and (5)-(7) will be changed to:

$$
\begin{gathered}
p\left(1-\frac{1}{\sigma}\right)=u w_{U}^{\theta} r^{1-\theta}, \\
p x=f w_{S}^{\alpha} r^{1-\alpha}+u w_{U}^{\theta} r^{1-\theta} x, \\
\alpha f w_{S}^{\alpha-1} r^{1-\alpha} n=\bar{L}_{S}, \\
{\left[(1-\alpha) f w_{S}^{\alpha} r^{-\alpha}+(1-\theta) u w_{U}^{\theta} r^{-\theta} x\right] n+a_{K A} A=\bar{K},} \\
\theta u w_{U}^{\theta-1} r^{1-\theta} x n+a_{L A} A=\bar{L}_{U} .
\end{gathered}
$$

So far, the new model has been built, which consists of eqs (4) and (13)-(17). Six endogenous variables, $w_{S}, r, w_{U}, x, n$, and $A$, are determined. The exogenous variables are $\bar{L}_{S}, \bar{K}$, and $\bar{L}_{U}$. All other variables are parameters. 
Proposition 3 can be established to depict the impacts exerted by international factor mobility on the skilled-unskilled wage gap.

Proposition 3: (i) An increase in skilled immigrants will decrease the wage rate of skilled labor and have no impact on the wage rate of unskilled labor, which leads to a reduced skilled-unskilled wage gap. (ii) An inflow of foreign capital will exert no impact on the wage rate of unskilled labor. If the capital to unskilled labor ratio in sector 2 is larger than (resp. smaller than) that in sector 1 , an inflow of foreign capital will raise (resp. reduce) the skilled wage rate, hence enlarging (resp. narrowing down) the skilled-unskilled wage gap. (iii) An increase in unskilled immigrants will not influence the wage rate of unskilled labor. If the capital to unskilled labor ratio in sector 2 is larger than (resp. smaller than) that in sector 1 , an increase in unskilled immigrants will decrease (resp. increase) the skilled wage rate, hence shrinking (resp. widening) the skilled-unskilled wage gap.

\section{Proof: See Appendix C.}

The economic intuition behind Proposition 3 can be stated as follows. From eqs (13) and (4), given the product prices of sectors 1 and 2, the wage rate of unskilled labor and the unit return of capital can be determined, which do not change with international factor mobility. An increase in skilled immigrants will raise the supply of skilled labor. Thus, given the demand for skilled labor in our assumed economy, the wage rate of skilled labor will decline. This leads to a reduction of the skilled-unskilled wage gap. We can see the validity of the first part of Proposition 3. However, for the second part, if the per capita capital in the monopolistically competitive sector is larger than that in the perfectly competitive sector (i.e. $\frac{\lambda_{K M}}{\lambda_{L M}}>\frac{\lambda_{K A}}{\lambda_{L A}}$ ), an inflow of foreign capital will enlarge the scale of the monopolistically competitive sector, leading to a growing demand for skilled labor. Given the supply of skilled labor, the wage rate of skilled labor will rise and the skilled-unskilled wage gap will be widened. If the opposite occurs (i.e. $\frac{\lambda_{K M}}{\lambda_{L M}}<\frac{\lambda_{K A}}{\lambda_{L A}}$ ), an inflow of foreign capital will shrink the monopolistically competitive sector, decreasing the demand for skilled labor. The consequences are that the wage rate of skilled labor will fall and that the skilled-unskilled wage inequality will be narrowed down. Similar to the analysis of the second part, we can easily get the establishment of the third part.

Remark 3: We would like to use $k_{S}$ and $k_{U}$ to equivalently show the conditions depicted by $\frac{\lambda_{K M}}{\lambda_{L M}}$ and $\frac{\lambda_{K A}}{\lambda_{L A}}$. One may argue that the cost function of sector 1 consists 
of three production factors, but for logic consistency, with loss some of its generality, we also use the ratio of the capital to that of skilled labor to denote the factor intensity. $\frac{\lambda_{K M}}{\lambda_{L M}}>(<) \frac{\lambda_{K A}}{\lambda_{L A}}$ is equivalent to $k_{S}-\omega k_{U} \frac{\theta u x w_{S}^{\theta} r^{1-\theta}}{a f w_{S}^{S} r^{1-\alpha}}>(<) 0$.

\subsection{Comparison of outcomes derived from three different models}

Now we use Table 1 to summarize our main findings.

Table 1: Comparison of impacts under different production cost components

\begin{tabular}{|c|c|c|c|c|c|c|c|c|c|}
\hline & \multicolumn{3}{|r|}{$\hat{\bar{L}}_{s}$} & \multicolumn{3}{|r|}{$\hat{\overline{\boldsymbol{K}}}$} & \multicolumn{3}{|r|}{$\hat{\bar{L}}_{U}$} \\
\hline & M1 & $E 1$ & $E 2$ & M1 & $E 1$ & $E 2$ & M1 & $E 1$ & $E 2$ \\
\hline$\hat{w}_{S}$ & 0 & - & - & 0 & + & $+(-)$ & 0 & - & $+(-)$ \\
\hline$\hat{w}_{U}$ & - & - & 0 & + & + & 0 & - & - & 0 \\
\hline$\hat{w}_{S}-\hat{w}_{U}$ & + & $+(-)$ & - & - & $+(-)$ & $+(-)$ & + & $+(-)$ & $+(-)$ \\
\hline
\end{tabular}

Notes: $M 1=$ Basic Model, $E 1=$ Extended Model 1 (Section 3.1), $E 2=$ Extended Model 2 (Section 3.2). "+": the change of exogenous variable and that of endogenous variable move in the same direction. "-": the change of exogenous variable and that of endogenous variable move in the opposite direction. " 0 ": the change of exogenous variable does not influence the endogenous variable. “+ $(-)$ ": the change of exogenous variable and that of endogenous variable conditionally move in the same (opposite) direction.

Table 1 indicates that production cost components of the monopolistically competitive sector matter for the impacts of international factor mobility on the skilled-unskilled wage inequality.

For consistency, it would be much better to use $k_{S} / k_{U}$ as the benchmark to compare how international factor mobility influences the wage gap. ${ }^{5}$ Given the same $k_{S} / k_{U}$, we want to find the differences of results among three models. Based on Remarks 1-3, related findings are summarized in Table 2.

5 Here, we would like to point out that it may not be reasonable to compare $k_{S}$ and $k_{U}$ under different production cost components directly. The reason for this is as follows: given other things (e.g. economic endowments and output prices) being equal, different cost components may lead to different values of $k_{S}$ and $k_{U}$. What we want to know is the following: given the same relative factor intensity between two sectors (i.e. $k_{S} / k_{U}$ ), what will the consequences be if we change the cost components of sector 1 ? Hence, we use the relative term, $k_{S} / k_{U}$, as the comparison benchmark. 
Table 2: Comparison of changes of wage gap $\left(\hat{w}_{S}-\hat{w}_{U}\right)$ based on $k_{S} / k_{U}$

\begin{tabular}{|c|c|c|c|c|c|c|c|}
\hline & & \multicolumn{3}{|r|}{$m_{1}<m_{2}$} & \multicolumn{3}{|r|}{$\boldsymbol{m}_{\mathbf{2}}<\boldsymbol{m}_{1}$} \\
\hline & & $\boldsymbol{k}_{S} / \boldsymbol{k}_{U}<\boldsymbol{m}_{1}$ & $\boldsymbol{m}_{\mathbf{1}}<\boldsymbol{k}_{\boldsymbol{S}} / \boldsymbol{k}_{\boldsymbol{U}}<\boldsymbol{m}_{\mathbf{2}}$ & $\boldsymbol{m}_{\mathbf{2}}<\boldsymbol{k}_{\boldsymbol{S}} / \boldsymbol{k}_{U}$ & $k_{S} / k_{U}<m_{2}$ & $\boldsymbol{m}_{\mathbf{2}}<\boldsymbol{k}_{\boldsymbol{S}} / \boldsymbol{k}_{U}<\boldsymbol{m}_{1}$ & $m_{1}<k_{S} / k_{U}$ \\
\hline \multirow[t]{3}{*}{$\hat{\bar{L}}_{S}$} & M1 & + & + & + & + & + & + \\
\hline & $E 1$ & + & - & - & + & + & - \\
\hline & $E 2$ & - & - & - & - & - & - \\
\hline \multirow[t]{3}{*}{$\hat{\bar{K}}$} & M1 & - & - & - & - & - & - \\
\hline & $E 1$ & - & + & + & - & - & + \\
\hline & $E 2$ & - & - & + & - & + & + \\
\hline \multirow[t]{3}{*}{$\hat{\bar{L}}_{u}$} & M1 & + & + & + & + & + & + \\
\hline & $E 1$ & + & - & - & + & + & - \\
\hline & $E 2$ & + & + & - & + & - & - \\
\hline
\end{tabular}

Notes: $M 1=$ Basic Model, $E 1=$ Extended Model 1 (Section 3.1), E2 = Extended Model 2 (Section 3.2). "+": the change of exogenous variable and that of endogenous variable move in the same direction. "-": the change of exogenous variable and that of endogenous variable move in the opposite direction. $m_{1}=\omega+\frac{f}{k_{U} \theta u x w_{S}^{\theta-1} r^{1-\theta}}>1$, and $m_{2}=\omega \frac{\theta u x w_{S}^{\theta} r^{1-\theta}}{\alpha f w_{S}^{r^{1-\alpha}}} \cdot m_{1}$ is derived from $E 1$, and $m_{2}$ is derived from E2. Hence, it is likely to see that $w_{S}$ as well as other endogenous variables has different values due to different cost structures when other things are equal or held constant. But the relative values of $k_{S} / k_{U}$ are comparable.

\section{Concluding remarks}

How international factor mobility influences the skilled-unskilled wage inequality has provoked great interests of many theoretical economists. However, whether different production cost components of the monopolistically competitive sector affect the change of wage inequality due to international factor mobility is seldom taken into account by the existing literature.

This paper tries to employ two-sector monopolistic competition models to investigate how international factor mobility influences the skilled-unskilled wage inequality in the presence of a monopolistically competitive sector with different production cost components. We conclude that differences in production cost components of the monopolistically competitive sector matter for the impacts of international factor mobility on the skilled-unskilled wage inequality. More specifically, factor components of the variable cost of the monopolistically sector determine the skilled-unskilled wage impacts exerted by international factor mobility. In addition to the production cost components considered by the present paper, one may argue that the production cost function of the monopolistically competitive sector may take the forms used by 
Anwar (2006, 2009). However, such a case has been investigated by Pi, Zhou, and Yin (2013), whose findings are almost the same as those in Section 3.1. Hence, our conclusions are robust.

Our findings show that the industrial upgrading process accompanied by the change of production cost components of certain industries is possibly a new channel that influences the wage inequality due to the growing international factor mobility. We try to clarify the conditions under which the wage inequality will be reduced or widened in the new background. For example, some industries may use unskilled labor and capital to produce before industrial upgrading and use skilled labor and capital after industrial upgrading. In this situation, the industrial upgrading process may possibly worsen the skilled-unskilled wage inequality, leading to latent social instability and other adverse effects. In order to weaken such negative impacts, some steps must be taken during the industrial upgrading process. For instance, the governments can take effective measures to promote the development of consumer service industries that have comparative advantages in open, competitive markets and are more beneficial to unskilled workers (Lin 2003, 2009, 2011).

In this paper, production cost components of the monopolistically competitive sector are exogenously given. The future research can discuss the changes of wage inequality due to international factor mobility in the situation where production cost components of the monopolistically competitive sector are endogenously determined. Additionally, the introduction of a third sector producing non-traded intermediate inputs for the final-good sector is also a good avenue for further research.

Acknowledgements: We would like to thank the editor Till Requate and three anonymous reviewers for their sincere help and suggestive comments on improving this paper. Particularly, we are grateful to the reviewers who encourage us to make consistent assumptions about the relative factor intensity and compare the final results based on the relative factor intensity. Pi acknowledges the financial support provided by the Program for New Century Excellent Talents in University.

\section{Appendices}

\section{Appendix A: Proof of Proposition 1}

From eq. (2), we know that $\hat{w}_{S}=0$. Therefore, international factor mobility has no impact on the wage rate of skilled labor. 
By totally differentiating eqs (3)-(7), we can get the following equation system:

$$
\left(\begin{array}{cc}
1 & 1 \\
-\frac{\lambda_{K A} \sigma_{A}}{\theta_{L A}} & \lambda_{K M}
\end{array}\right)\left(\begin{array}{l}
\hat{r} \\
\hat{n}
\end{array}\right)=\left(\begin{array}{l}
1 \\
0
\end{array}\right) \hat{\bar{L}}_{S}+\left(\begin{array}{l}
0 \\
1
\end{array}\right) \hat{\bar{K}}+\left(\begin{array}{c}
0 \\
-\lambda_{K A}
\end{array}\right) \hat{\bar{L}}_{U} .
$$

where $\sigma_{A}$ is the factor substitution elasticity of sector 2, $\theta_{L A}$ is the distributive share of unskilled labor employed by sector 2 (i.e. $\theta_{L A}=a_{L A} w_{U}$ ), $\lambda_{K M}$ and $\lambda_{K A}$ represent the allocative shares of capital employed by sectors 1 and 2, respectively (e.g. $\lambda_{K A}=\frac{a_{K A} A}{K}$ ), and " $\wedge$ " represents the relative rate of the change of the variable (e.g. $\hat{r}=\frac{d r}{r}$ ).

Denote the coefficient matrix of the above equation system as $\Delta_{1}$, and we have

$$
\Delta_{1}=\lambda_{K M}+\frac{\lambda_{K A} \sigma_{A}}{\theta_{L A}}>0
$$

Thus, the established economic system is stable. Using the Cramer's rule to solve the above equation system, we get

$$
\frac{\hat{r}}{\overline{\bar{L}}_{S}}=\frac{\lambda_{K M}}{\Delta_{1}}>0, \frac{\hat{r}}{\hat{\bar{K}}}=\frac{-1}{\Delta_{1}}<0, \text { and } \frac{\hat{r}}{\hat{\bar{L}}_{U}}=\frac{\lambda_{K A}}{\Delta_{1}}>0 .
$$

Total differentiation of eq. (4) yields

$$
\hat{w}_{U}=-\frac{\theta_{K A}}{\theta_{L A}} \hat{r}
$$

Therefore, from eq. (19) to eq. (21), we obtain the following results:

$$
\begin{gathered}
\frac{\hat{w}_{S}}{\hat{\bar{L}}_{S}}=0, \frac{\hat{w}_{U}}{\hat{\bar{L}}_{S}}<0, \text { and thus } \frac{\hat{w}_{S}-\hat{w}_{U}}{\hat{\bar{L}}_{S}}>0 . \\
\frac{\hat{w}_{S}}{\hat{\bar{K}}}=0, \frac{\hat{w}_{U}}{\hat{\bar{K}}}>0 \text {, and thus } \frac{\hat{w}_{S}-\hat{w}_{U}}{\hat{\bar{K}}}<0 . \\
\frac{\hat{w}_{S}}{\hat{\bar{L}}_{U}}=0, \frac{\hat{w}_{U}}{\hat{\bar{L}}_{U}}<0, \text { and thus } \frac{\hat{w}_{S}-\hat{w}_{U}}{\hat{\bar{L}}_{U}}>0 .
\end{gathered}
$$




\section{Appendix B: Proof of Proposition 2}

Taking total differentiation of eqs (2), (9), (4), (10), (11), and (7), and substituting the differentiated eqs (2), (9), (4), and (7) into eqs (10) and (11) yield

$$
\left(\begin{array}{cc}
\frac{1}{\theta} & 1 \\
-\frac{\lambda_{K A} \sigma_{A}}{\theta_{L A}} & \lambda_{K M}
\end{array}\right)\left(\begin{array}{l}
\hat{r} \\
\hat{n}
\end{array}\right)=\left(\begin{array}{l}
1 \\
0
\end{array}\right) \hat{\bar{L}}_{S}+\left(\begin{array}{l}
0 \\
1
\end{array}\right) \hat{\bar{K}}+\left(\begin{array}{c}
0 \\
-\lambda_{K A}
\end{array}\right) \hat{\bar{L}}_{U}
$$

Denote the coefficient matrix of the above equation system as $\Delta_{2}$, and we have

$$
\Delta_{2}=\frac{\lambda_{K M}}{\theta}+\frac{\lambda_{K A} \sigma_{A}}{\theta_{L A}}>0 .
$$

Using the Cramer's rule to solve the above equation system, we get

$$
\frac{\hat{r}}{\hat{\bar{L}}_{S}}=\frac{\lambda_{K M}}{\Delta_{2}}>0, \frac{\hat{r}}{\hat{\bar{K}}}=\frac{-1}{\Delta_{2}}<0, \text { and } \frac{\hat{r}}{\hat{\bar{L}}_{U}}=\frac{\lambda_{K A}}{\Delta_{2}}>0 .
$$

It is not hard to verify that $\frac{1-\theta}{\theta}$ is the relative capital-skilled-labor distributive share in sector 1 and that $\frac{\theta_{K A}}{\theta_{L A}}$ is the relative capital-unskilled-labor distributive share in sector 2 .

With the help of the proof of Proposition 1 and eqs (23) and (24), we obtain

$$
\frac{\hat{w}_{S}}{\hat{\bar{L}}_{S}}<0, \frac{\hat{w}_{U}}{\hat{\bar{L}}_{S}}<0
$$

If $\frac{1-\theta}{\theta}>\frac{\theta_{K A}}{\theta_{L A}}$, then $\frac{\hat{w}_{S}-\hat{w}_{U}}{\hat{L}_{S}}<0$; and if $\frac{1-\theta}{\theta}<\frac{\theta_{K A}}{\theta_{L A}}$, then $\frac{\hat{w}_{S}-\hat{w}_{U}}{\hat{L}_{S}}>0$.

$$
\frac{\hat{w}_{S}}{\hat{\bar{K}}}>0, \frac{\hat{w}_{U}}{\hat{\bar{K}}}>0
$$

If $\frac{1-\theta}{\theta}>\frac{\theta_{K A}}{\theta_{L A}}$, then $\frac{\hat{w}_{S}-\hat{w}_{U}}{\hat{K}}>0$; and if $\frac{1-\theta}{\theta}<\frac{\theta_{K A}}{\theta_{L A}}$, then $\frac{\hat{w}_{S}-\hat{w}_{U}}{\hat{K}}<0$.

$$
\frac{\hat{w}_{S}}{\hat{\bar{L}}_{U}}<0, \frac{\hat{w}_{U}}{\hat{\bar{L}}_{U}}<0
$$

If $\frac{1-\theta}{\theta}>\frac{\theta_{K A}}{\theta_{L A}}$, then $\frac{\hat{w}_{S}-\hat{w}_{U}}{\hat{L}_{U}}<0$; and if $\frac{1-\theta}{\theta}<\frac{\theta_{K A}}{\theta_{L A}}$, then $\frac{\hat{w}_{S}-\hat{w}_{U}}{\hat{L}_{U}}>0$.

\section{Appendix C: Proof of Proposition 3}

From eqs (4) and (13), we obtain $\hat{w}_{U}=0$. Thus, $\frac{\hat{w}_{U}}{\hat{L}_{S}}=0$, $\frac{\hat{w}_{U}}{\hat{\bar{K}}}=0$, and $\frac{\hat{w}_{U}}{\hat{L}_{U}}=0$. Total differentiation of eqs (14)-(17) yields the following equation system: 


$$
\left(\begin{array}{ccc}
\alpha-1 & 1 & 0 \\
\alpha \lambda_{L M} & \lambda_{L M} & \lambda_{L A} \\
\alpha \lambda_{K M} & \lambda_{K M} & \lambda_{K A}
\end{array}\right)\left(\begin{array}{c}
\hat{w}_{S} \\
\hat{n} \\
\hat{A}
\end{array}\right)=\left(\begin{array}{l}
1 \\
0 \\
0
\end{array}\right) \hat{\bar{L}}_{S}+\left(\begin{array}{l}
0 \\
0 \\
1
\end{array}\right) \hat{\bar{K}}+\left(\begin{array}{l}
0 \\
1 \\
0
\end{array}\right) \hat{\bar{L}}_{U}
$$

Denote the coefficient matrix of the above equation system as $\Delta_{3}$, and we have

$$
\Delta_{3}=-\left(\lambda_{L M} \lambda_{K A}-\lambda_{L A} \lambda_{K M}\right) .
$$

However, the sign of $\Delta_{3}$ is indefinable. If $\frac{\lambda_{K A}}{\lambda_{L A}}-\frac{\lambda_{K M}}{\lambda_{L M}}>0$, then $\Delta_{3}<0$. If $\frac{\lambda_{K A}}{\lambda_{L A}}-\frac{\lambda_{K M}}{\lambda_{L M}}<0$, then $\Delta_{3}>0$. It is worth noting here that $\frac{\lambda_{K M}}{\lambda_{L M}}$ is the ratio of the amount of capital to that of unskilled labor of sector 1 , that is, the capital to unskilled labor ratio in sector 1. $\frac{\lambda_{K A}}{\lambda_{L A}}$ is the ratio of the amount of capital to that of unskilled labor of sector 2, that is, the capital to unskilled labor ratio in sector 2.

Using the Cramer's rule to solve the above equation system, we get

$$
\frac{\hat{w}_{S}}{\hat{\bar{L}}_{S}}=-1<0, \frac{\hat{w}_{S}}{\hat{\bar{K}}}=\frac{\lambda_{L A}}{\Delta_{3}} \text {, and } \frac{\hat{w}_{S}}{\hat{\bar{L}}_{U}}=\frac{-\lambda_{K A}}{\Delta_{3}} .
$$

Furthermore, we have

$$
\frac{\hat{w}_{S}-\hat{w}_{U}}{\hat{\bar{L}}_{S}}<0 .
$$

If $\frac{\lambda_{K A}}{\lambda_{L A}}-\frac{\lambda_{K M}}{\lambda_{L M}}<0$, then $\frac{\hat{w}_{S}-\hat{w}_{U}}{\hat{K}}>0$; and if $\frac{\lambda_{K A}}{\lambda_{L A}}-\frac{\lambda_{K M}}{\lambda_{L M}}>0$, then $\frac{\hat{w}_{S}-\hat{w}_{U}}{\hat{K}}<0$.

If $\frac{\lambda_{K A}}{\lambda_{L A}}-\frac{\lambda_{K M}}{\lambda_{L M}}>0$, then $\frac{\hat{w}_{S}-\hat{w}_{U}}{\hat{L}_{U}}<0$; and if $\frac{\lambda_{K A}}{\lambda_{L A}}-\frac{\lambda_{K M}}{\lambda_{L M}}<0$, then $\frac{\hat{w}_{S}-\hat{w}_{U}}{\hat{L}_{U}}>0$.

\section{References}

Anwar, S. 2006. "Factor Mobility and Wage Inequality in the Presence of Specialization-Based External Economies." Economics Letters 93(1):88-93.

Anwar, S. 2008. "Factor Mobility, Wage Inequality and Welfare." International Review of Economics and Finance 17(4):495-506.

Anwar, S. 2009. "Sector Specific Foreign Investment, Labor Inflow, Economies of Scale and Welfare." Economic Modelling 26(3):626-30.

Anwar, S. 2010. "Wage Inequality, Increased Competition, and Trade Liberalization: Short Run Vs Long Run." Review of International Economics 18(3):574-81.

Anwar, S., and S. Sun. 2012. "Trade Liberalisation, Market Competition and Wage Inequality in China's Manufacturing Sector." Economic Modelling 29(4):1268-77.

Arora, A., and A. Gambardella. 2004. "The Globalization of the Software Industry: Perspectives and Opportunities for Developed and Developing Countries." NBER working paper, No. 10538. 
Baldwin, R. E. 2008. "Sequencing and Depth of Regional Economic Integration: Lessons for the Americas from Europe.” World Economy 31(1):5-30.

Beladi, H., S. Chaudhuri, and S. Yabuuchi. 2008. "Can International Factor Mobility Reduce Wage Inequality in a Dual Economy?" Review of International Economics 16(5):893-903.

Beladi, H., S. Kar, and S. Marjit. 2013. "Emigration, Finite Changes and Wage Inequality." Economics \& Politics 25(1):61-71.

Beladi, H., S. Marjit, and U. Broll. 2011. "Capital Mobility, Skill Formation and Polarization.” Economic Modelling 28(4):1902-06.

Berman, E., J. Bound, and S. Machin. 1998. "Implications of Skill-Biased Technological Change: International Evidence." Quarterly Journal of Economics 113(4):1245-80.

Berman, E., and S. Machin. 2000. "Skill-Biased Technology Transfer around the World." Oxford Review of Economic Policy 16(2):12-22.

Chao, C.-C., B. Hazari, and E. H. S. Yu. 2006. "Rising Wage Inequality in Developing Economies: Privatization and Competition." Journal of International Trade and Economic Development 15(3):375-85.

Chao, C.-C., J.-P. Laffargu, and P. M. Sgro. 2012. "Environmental Control, Wage Inequality and National Welfare in a Tourism Economy." International Review of Economics and Finance 22(1):201-07.

Chaudhuri, S., 2008. "Wage inequality in a dual economy and international mobility of factors: Do factor intensities always matter?." Economic Modelling 25(6):1155-1164.

Chaudhuri, S., and D. Banerjee. 2010. "Foreign Capital Inflow, Skilled-Unskilled Wage Inequality and Unemployment of Unskilled Labour in a Fair Wage Model." Economic Modelling 27(1):477-86.

Chaudhuri, S., and S. Yabuuchi. 2007. "Economic Liberalization and Wage Inequality in the Presence of Labor Market Imperfection." International Review of Economics and Finance 16(4):592-603.

Chen, M. X. 2009. "Regional Economic Integration and Geographic Concentration of Multinational Firms." European Economic Review 53(3):355-75.

Combes, P.-P., T. Mayer, and J.-F. Thisse. 2008. Economic Geography: The Integration of Regions and Nations. Princeton, NJ: Princeton University Press.

Das, S. P. 2002. "Foreign Direct Investment and the Relative Wage in a Developing Country." Journal of Development Economics 67(1):55-77.

Das, S. P. 2005. "Gradual Globalization and Inequality Between and within Countries." Canadian Journal of Economics 38(3):852-69.

Dixit, A. K., and J. E. Stiglitz. 1977. "Monopolistic Competition and Optimum Product Diversity." American Economic Review 67(3):297-308.

Epifani, P., and G. A. Gancia. 2008. "The Skill Bias of World Trade." Economic Journal 118(530):927-60.

Eriksson, T., M. Pytliková, and F. Warzynski. 2013. "Increased Sorting and Wage Inequality in the Czech Republic." Economics of Transition 21(2):357-80.

Feenstra, R. C., and G. H. Hanson. 1996. "Foreign Investment, Outsourcing and Relative Wages." In Political Economy of Trade Policies: Essays in Honor of Jagdish N. Bhagwati, edited by R. Feenstra, G. Grossman, and D. Irwin. Cambridge, MA: MIT Press.

Feenstra, R. C., and G. H. Hanson. 2003. "Global Production Sharing and Rising Wage Inequality: A Survey of Trade and Wages." In Handbook of International Trade, edited by K. Choi and J. Harrigan. London: Basil Blackwell. 
Figini, P. 2011. "Does Foreign Direct Investment Affect Wage Inequality? An Empirical Investigation." World Economy 34(9):1455-75.

Friedberg, R. M., and J. Hunt. 1995. "The Impact of Immigrants on Host Country Wages, Employment and Growth." Journal of Economic Perspectives 9(2):23-44.

Fujita, M., P. Krugman, and A. J. Venables. 1999. The Spatial Economy: Cities, Regions, and International Trade. Cambridge, MA: MIT Press.

Helpman, E., and P. Krugman. 1985. Market Structure and Foreign Trade: Increasing Returns, Imperfect Competition, and the International Economy. Cambridge, MA: MIT Press.

Lin, J. Y. 2003. “Development Strategy, Viability and Economic Convergence.” Economic Development and Cultural Change 53(2):277-308.

Lin, J. Y. 2009. Economic Development and Transition: Thought, Strategy, and Viability. Cambridge: Cambridge University Press.

Lin, J. Y. 2011. “New Structural Economics: A Framework for Rethinking Development.” World Bank Research Observer 26(2):193-221.

Marjit, S., H. Beladi, and A. Chakrabarti. 2004. "Trade and Wage Inequality in Developing Countries.” Economic Inquiry 42(2):295-303.

Marjit, S., and S. Kar. 2005. "Emigration and Wage Inequality." Economics Letters 88(1):141-45.

Marjit, S., and S. Kar. 2011. "Emigration, Finite Changes and Wage Inequality." Discussion Papers Series 423, School of Economics, University of Queensland, Australia.

McNabb, R., and R. Said. 2013. "Trade Openness and Wage Inequality: Evidence for Malaysia." Journal of Development Studies 49(8):1-15.

Mehta, A., and R. Hasan. 2012. "The Effects of Trade and Services Liberalization on Wage Inequality in India." International Review of Economics and Finance 23:75-90.

Mishra, P. 2007. "Emigration and Wages in Source Countries: Evidence from Mexico." Journal of Development Economics 82(1):180-99.

Oladi, R., and H. Beladi. 2007. "International Migration and Real Wages." Economics Bulletin 6(30):1-8.

Oladi, R., and J. Gilbert. 2011. "Monopolistic Competition and North-South Trade." Review of International Economics 19(3):459-74.

Oladi, R., J. Gilbert, and H. Beladi. 2011. "Foreign Direct Investment, Non-Traded Goods and Real Wages." Pacific Economic Review 16(1):36-41.

Pan, L., and Y. Zhou. 2013. "International Factor Mobility, Environmental Pollution and SkilledUnskilled Wage Inequality in Developing Countries.” Economic Modelling 33:826-31.

Pi, J., and Y. Zhou. 2012. "Public Infrastructure Provision and Skilled-Unskilled Wage Inequality in Developing Countries." Labour Economics 19(6):881-87.

$\mathrm{Pi}$, J., and Y. Zhou. 2013. "Institutional Quality and Skilled-Unskilled Wage Inequality." Economic Modelling 35:356-63.

Pi, J., and Y. Zhou. 2014. "Foreign Capital, Public Infrastructure, and Wage Inequality in Developing Countries." International Review of Economics and Finance 29:195-207.

Pi, J., Y. Zhou, and J. Yin. 2013. "International Factor Mobility, Monopolistic Competition, and Wage Inequality.” Economic Modelling 33:326-32.

Sen, P., A. Ghosh, and A. Barman. 1997. "The Possibility of Welfare Gains with Capital Inflows in a Small Tariff-Ridden Economy." Economica 64(254):345-52.

Wood, A. 1997. "Openness and Wage Inequality in Developing Countries: The Latin American Challenge to East Asian Conventional Wisdom." World Bank Economic Review 11(1):33-57. 
Wu, X. 2001. "The Impact of Foreign Direct Investment on the Relative Return to Skill." Economics of Transition 9(3):695-715.

Yabuuchi, S., and S. Chaudhuri. 2007. "International Migration of Labor and Skilled-Unskilled Wage Inequality in a Developing Economy.” Economic Modelling 24(1):128-37.

Zhang, J. 2012. "Inflow of Labour, Producer Services and Wage Inequality." Economics Letters 117(3):600-03.

Zhang, J. 2013. "Factor Mobility and Skilled-Unskilled Wage Inequality in the Presence of Internationally Traded Product Varieties." Economic Modelling 30:579-85. 